\title{
Monitorando a Comunicação na CV-Muzar com o Uso de Agentes Inteligentes
}

\author{
Ana Carolina Bertoletti De Marchi ${ }^{1}$ \\ Roberto dos Santos Rabello ${ }^{1}$ \\ Afonso Alban ${ }^{1}$ \\ Vinícius Andrei Cerbaro ${ }^{1}$ \\ Juliano Mauricio Bordignon ${ }^{1}$
}

\begin{abstract}
Resumo: Este artigo descreve o Sistema Multiagente (SMA) proposto para monitorar a conversação na ferramenta de bate-papo da Comunidade Virtual do Muzar (CV-Muzar). Para tanto, são analisados os marcadores conversacionais e sua aplicação em ambientes de conversação síncrona, com vistas a propor mecanismos de compensação para os déficits de comunicação identificados. O SMA proposto conta com cinco agentes cooperativos que monitoram as conversas em tempo real e interferem na interface de conversação para aconselhar e, se necessário, advertir o participante.
\end{abstract}

Palavras-chave: Sistema multiagente. Comunidades virtuais. Agentes inteligentes.

\begin{abstract}
This article describes a Multiagent System (MAS) proposed to monitor conversations in the chat tool of the Muzar Virtual Community (Comunidade Virtual do Muzar, CV-Muzar). Thus, conversational markers and their use in synchronous chat environment are being analyzed to propose a compensation mechanism for the identified communication deficits. The proposed MAS has five cooperative agents that monitor conversations in real time and interfere with the chat interface to advice and, if necessary, warn the participant.
\end{abstract}

Keywords: Multiagent system. Virtual communities. Intelligent agents.

\section{Introdução}

O desejo de ampliar o canal comunicativo dos museus, oferecendo aos visitantes um espaço de encontros e convivências, que rompem fronteiras geográficas e temporais, desencadeou uma série de estudos que viabilizou a construção da CV-Muzar - Comunidade Virtual do Muzar/UPF [1].

A CV-Muzar foi projetada de forma a envolver cada vez mais o visitante do museu e torná-lo cúmplice da experiência vivenciada, acabando com o destinatário passivo do discurso expositivo que se estabelecia unilateralmente. Nesse espaço, o visitante virtual tem acesso a um conjunto de objetos de aprendizagem e condições facilitadas para: a) a experimentação de recursos; b) a construção de problemas/soluções; c) o compartilhamento de ideias; d) a construção do acervo junto aos profissionais; e) a formação de discussões intelectuais.

A partir do ambiente construído, várias experimentações foram realizadas com visitantes virtuais dispersos geograficamente. Nesses momentos, foi possível identificar melhorias a serem implantadas, dentre as quais a necessidade de formar grupos menores de discussão mais pontuais. A formação de grupos dentro da CV-Muzar possibilitou: a) a aprendizagem em grupo como o intuito de desenvolver e de melhorar habilidades individuais para o uso do conhecimento; b) a aceitação de responsabilidades pelo aprendizado individual e do grupo; c) o desenvolvimento de capacidades para refletir sobre as suas próprias suposições, expressando suas ideias para o grupo; d) o desenvolvimento de habilidades sociais e

\footnotetext{
${ }^{1}$ Curso de Ciência da Computação, UPF, Campus 1 - BR 285 - Passo Fundo (RS) - Brasil

\{carolina, rabello, 97528,97578,83485@upf.br\}

doi: $10.5335 /$ rbca. 2010.006
}

Revista Brasileira de Computação Aplicada (ISSN 2176-6649), Passo Fundo, v.2, n. 1, p. 57-68, mar. 201057 
de grupo. Para tanto, foi utilizada a tecnologia de sistemas multiagentes por automatizar as tarefas que deveriam ser realizadas por profissionais quanto à formação e à coordenação dos grupos [2].

No entanto, apenas a automatização na formação dos grupos não foi suficiente para identificar e corrigir pequenas falhas de interação entre os participantes da comunidade, principalmente no que se refere à conversação síncrona nos bate-papos. A conversação é um dos elementos da comunicação em que os interlocutores podem interagir e efetuar trocas que acabarão, normalmente, no desenvolvimento cognitivo. Uma conversação não bem-sucedida pode caracterizar dificuldades de sociabilização dentro de uma comunidade, gerando, muitas vezes, interpretações equivocadas. Tais interpretações podem ferir, pelo menos, três dos doze princípios das comunidades virtuais apontadas por Mongoose [3]: i) a reputação; ii) a comunicação; iii) a confiança entre os participantes.

$\mathrm{Na}$ comunicação, seja verbal, seja não verbal, os marcadores são importantes para garantir uma fluência, lógica e compreensão do processo conversacional. Esses marcadores são palavras ou expressões bastante estereotipadas, que aparecem no contexto geral, particular ou pessoal da conversação e não dependem especialmente de novas informações para o desenvolvimento do tópico.

Nesse sentido, diante da importância da comunicação para a interação social dentro de uma comunidade virtual, busca-se com este trabalho propor um sistema multiagente que auxilie na análise dos marcadores verbais nos bate-papos realizados na CV-Muzar, com vistas a propor mecanismos de compensação para os déficits de comunicação identificados.

Diante desse contexto, este artigo está organizado em seções: primeiramente, será discutido o papel da comunicação em comunidades virtuais; após, será apresentado o conceito de marcadores conversacionais e sua aplicação em ambientes de conversação síncrona; por fim, a estrutura do Sistema Multiagente proposto para a CV-Muzar será apresentado na quinta seção.

\section{O Papel da Comunicação em uma Comunidade Virtual}

Os processos comunicativos entre os seres humanos iniciaram por uma necessidade de cooperação, porque precisavam encontrar uma forma de unir esforços em busca de objetivos comuns para que a sobrevivência da espécie fosse garantida. A comunicação possibilitou e efetivou a criação dos elos de que os semelhantes necessitavam.

De acordo com Watzlawick, Beavin e Jackson [4], se todo o comportamento, numa situação interacional, tem valor de mensagem, ou seja, é comunicação, isso indica que, por mais que o indivíduo se esforce, é impossível não comunicar. Ainda de acordo com estes autores, até a própria inatividade ou o silêncio agregam a eles um valor de mensagem.

Todavia, não se pode dizer que a comunicação só acontece quando existe intencionalidade, ou quando é consciente ou bem-sucedida, isto é, quando ocorre uma compreensão mútua.

[...] se a mensagem enviada iguala a mensagem recebida é importante, mas diferente ordem de análise, pois que deve assentar, fundamentalmente, nas avaliações de dados específico, introspectivos, relatados pelo sujeito, os quais preferimos negligenciar para a exposição de uma teoria comportamental de comunicação [4].

Para que haja troca comunicativa, não basta que dois ou mais indivíduos falem de forma alternada; é preciso que todos os participantes estejam envolvidos na troca e engajados com o processo, recorrendo aos diversos procedimentos de validação interlocutória. Os cumprimentos, as apresentações, as saudações e outros rituais desempenham um papel importante, mas a validação interlocutória se consolida por meios importantes [5], a saber: a) o emissor; b) o receptor; c) a sincronização interacional, que se identifica, principalmente, pelo funcionamento dos turnos de fala, comportamentos corporais dos participantes da interação, escolhas dos temas, registro de troca, entre outros.

A comunicação é central para a interação social e pode interferir significativamente no desempenho escolar, no profissional ou na comunicação social. Quando o indivíduo se comunica permite ao outro que 
conheça seus pensamentos, sentimentos, necessidades e passa a conhecer os sentimentos, os pensamentos e as necessidades do outro. Podemos nos comunicar com o outro escrevendo, dizendo, representando ou mesmo gesticulando. Todas essas formas de comunicação podem ser agrupadas, por alguns estudiosos, no comportamento verbal e constituem uma aquisição recente da espécie humana.

Nos dias atuais, além da leitura, da escrita, da fala e dos gestos, contamos com um novo espaço comunicacional, que desestabilizou os modos tradicionais de comunicação e trouxe processos provocadores de rupturas, como a interatividade, o inter-relacionamento de conhecimentos, numa relação nova de conceitos: de contexto, de espaço e de tempo das mensagens entre autores e leitores. Esse novo espaço se caracteriza como a comunicação que se dá entre seres humanos através da instrumentalização de computadores, denominado por Herring [6] como Comunicação Mediada por Computador (CMC).

A CMC pode ocorrer em diversas modalidades, tais como textual, gráfica, auditiva e visual. Neste trabalho iremos nos deter na CMC baseada em textos. Os participantes da CV-Muzar interagem por meio da palavra escrita, digitando mensagens que são simultaneamente lidas por outras pessoas em suas respectivas telas de vídeo - CMC síncrona (chat).

Nos chats (também denominados salas de bate-papo) a comunicação é dinâmica, interativa e síncrona. Esse sincronismo possibilita que pessoas geograficamente distantes dialoguem em tempo real, o que proporciona que sejam estabelecidas relações com um grande número de pessoas ao mesmo tempo. O chat é uma das ferramentas mais poderosas para a interação mútua, pois, em virtude da velocidade de intercâmbio de mensagens textuais, com ou sem imagem anexada, oferece um palco para diálogo de alta intensidade e para a aproximação de interagentes sem qualquer proximidade física, levando à rápida construção de relações sociais.

O chat pode simular um diálogo oral que não é mais oral, mas escrito, escrito de modo oralizado e, na maioria das vezes, coloquial. Segundo Reid [7], o chat é "uma forma de comunicação escrita, - ou melhor digitada, que é transmitida, recebida e respondida dentro de um período de tempo que tem sido formalmente relevante apenas para a comunicação falada."

Para Doell em Recuero [8], o chat apresenta uma linguagem híbrida, que possui características tanto da linguagem escrita quanto da linguagem oral. $\mathrm{O}$ autor acredita que o discurso no chat possui uma característica mais "oral", em razão do uso de convenções como elementos paralinguísticos (como a linguagem não verbal), a imitação de dialetos e o uso de entonação. Essa característica híbrida deve-se ao fato de que no chat digitamos em um teclado e as pessoas leem. Entretanto, por causa da forma coloquial e da mudança rápida das letras da tela, é mais que falar. Na verdade, como diz Coate em [8], "É falar pela escrita".

Os chats virtualizam elementos da oralidade e da escrita com a possibilidade de utilizar sinais que auxiliam os outros a interpretar aquilo que foi dito, acrescentando emoções. Através desse canal de interação mútua, os interagentes constroem uma relação entre si; debatem diferentes temas em uma velocidade que pode se aproximar de um encontro face a face; negociam o encaminhamento da interação e, possivelmente, criam suas próprias regras. Os chats, juntamente com as demais modalidades de CMC, vêm proporcionando o surgimento de novas formas de sociabilidade, nas quais indivíduos se aglutinam em torno de interesses comuns, independentemente das distâncias espaciais. Para Lévy [9, p.20], a virtualização da linguagem reinventa uma cultura, atingindo até mesmo as modalidades do estar junto, o que fez surgir novos meios de interações sociais, como as comunidades virtuais (CV). Para o autor, uma comunidade virtual "vive sem lugar de referência estável, em toda a parte onde se encontrem seus membros móveis... ou em parte alguma".

As CVs fazem uso de grande parte do potencial comunicativo dos computadores, utilizando para isso os instrumentos virtualizantes da linguagem como e-mail, chat e hipertexto. As CVs virtualizam as relações interpessoais graças à virtualização da linguagem. Para Carvalho em [10], "os homens realizam comunidade pelo fato mesmo de que uns como os outros se comunicam". Nesse caso, a linguagem corresponde a um meio de comunicação utilizado por uma comunidade para estabelecer interações sociais.

Dessa forma, "o processo estrutural que é associado com a comunidade é a comunicação. Sem comunicação não pode haver ação para organizar as relações sociais" [11]. As trocas realizadas nas interações sociais são parte do processo social de estabelecer contato com outros indivíduos. Por isso, a comunicação é essencial para a organização social.

Nesse sentido, quando falamos em comunidade virtual, estamos envolvendo um complexo processo onde relações e interações são estabelecidas de uma nova forma entre diferentes pessoas. No ciberespaço, a comunicação assume um papel ainda mais evidente, como define [8]: “O ciberespaço é comunicação e só existe 
enquanto uma quantidade de informações estiver circulando entre os computadores que estão conectados pela Internet". Portanto, a comunicação é um elemento fundamental para a socialização no ciberespaço e essencial para a socialização de qualquer indivíduo.

Na CV-Muzar, por priorizarmos a comunicação para a interação social, muitas funcionalidades foram automatizadas com o uso de agentes inteligentes. Neste trabalho será apresentada a estrutura de agentes projetada para auxiliar na conversação online, por meio dos marcadores conversacionais.

\section{Marcadores Conversacionais}

De acordo com [12], existem relações estruturais e linguísticas entre a organização da conversação em turnos e a ligação interna em unidades constitutivas de turno. Os marcadores do texto possuem funções tanto conversacionais quanto sintáticas e podem ser divididos em três categorias: verbais, não verbais e suprassegmentais. Os marcadores podem funcionar como iniciadores de turno ou unidade comunicativa, ou como finalizadores.

A ideia de turno está ligada às várias situações em que os membros de um grupo se alternam ou se sucedem na consecução de um objetivo comum. Assim, na análise da conversação podemos entender turno como aquilo que um falante faz ou diz enquanto tem a palavra, incluindo também a possibilidade de silêncio. $\mathrm{O}$ turno trata-se de qualquer intervenção do interlocutor.

Marcadores são palavras ou expressões bastante estereotipadas, que aparecem no contexto geral, particular ou pessoal da conversação e não dependem especialmente de novas informações para o desenvolvimento do tópico. Os recursos não verbais, tais como o riso, o olhar e franzimento da testa, ocupam um lugar importante na interação face a face e têm a função de estabelecer, manter e regular o contato.

Por sua vez, os recursos suprassegmentais são de natureza linguística e não verbal, como as pausas e o tom de voz. As pausas podem influenciar as mudanças de turno nas conversações informais, e uma demarcação dessas pausas é sempre importante para uma análise da conversação. As pausas podem ter duração diferente, ou seja, podem ser curtas, médias ou longas, e constituem um fator decisivo na organização do texto conversacional. Além das pausas, o tom de voz, a entonação, a cadência e a velocidade também fazem parte dos recursos suprassegmentais, que podem caracterizar e marcar relações pessoais e de conteúdo.

De acordo com [12], os sinais verbais podem ser divididos em duas categorias, que são sinais do falante e sinais do ouvinte, e cada um deles pode ter funções conversacionais e funções sintáticas. As funções conversacionais são consideradas em dois aspectos:

- $\quad$ sinais produzidos pelo falante, que, geralmente, servem para manter o turno;

- $\quad$ sinais produzidos pelo ouvinte, que funcionam dentro do turno de um interlocutor e muitas vezes em sobreposição, servindo para dar orientação ao falante em relação à recepção.

As funções sintáticas podem se responsabilizar não somente pela sintaxe da interação, mas também pela segmentação e pelo encadeamento de estruturas linguísticas, o que pode provocar uma forte relação entre a sintaxe da interação e a gramatical. As posições dos sinais variam de acordo com o falante ou o ouvinte, sendo que os sinais do falante podem aparecer no início, no meio ou no fim do turno; já os sinais do ouvinte, de modo geral, aparecem na concordância com o tópico ou na discordância.

Quanto às posições, os sinais do falante podem vir tanto no início quanto no desenvolvimento ou final de turno, enquanto o ouvinte vem, normalmente, no ponto de discordância ou concordância com os sinais do falante e normalmente se localiza no desenvolvimento do diálogo.

Para estabelecer uma conversação síncrona no bate-papo, duas ou mais pessoas devem partilhar um mínimo de conhecimento em comum, visto que toda a conversação acontece mediante alguma circunstância ou contexto em que os participantes estão envolvidos. Segundo [12], o mais comum é que uma conversão tenha, pelo menos, três seções distintas estruturalmente, ou seja, uma abertura, um desenvolvimento e um fechamento.

Os marcadores conversacionais são de relevante importância, pois ajudam a construir e dar coerência e coesão, funcionando como articuladores e determinando as expressões de interação entre os interlocutores. 
Quanto a sua forma, os marcadores podem ser verbais ou não verbais. Os verbais podem ser lexicados, ou seja, compostos por palavras como "sabe?"; "eu acho que"; ou não lexicados, com expressões do tipo "ahn", "eh", etc. Os não verbais podem ser as pausas mais alongadas e as ênfases em frases ou sílabas para demarcação.

$\mathrm{Na}$ questão semântica, a maioria desses marcadores não apresenta nenhuma importância para o entendimento do texto. Às vezes, expressões como "eu acho que" e "eu tenho a impressão" não contribuem efetivamente para o desenvolvimento do tópico conversacional (assunto), mas têm como função revelar um ponto de vista do falante ou testar o grau de atenção do ouvinte.

Esses marcadores podem desempenhar funções mais genéricas, como de articuladores e estruturadores, e funções mais específicas, de monitoramento do ouvinte, da busca de aprovação, sinalizadores de hesitação, de atenuação ou de reformulação, além da intenção e interação do falante.

Existem marcadores de dois tipos: os de interação e os de processamento. Os marcadores conversacionais de interação são produzidos pelo falante e pelo ouvinte e são sempre "conjunto de partículas, palavras, sintagmas, expressões estereotipadas e orações ou, ainda, expressões lexicalizadas". É o caso de "então", “né”, "veja bem”, “você não acha?", “sim”, “claro”, “com certeza”, “ah sim”, “e aí?”, “duvido!”, "mesmo!", "hum", entre diversos outros elementos. Tais marcadores podem vir dentro do turno ou na sequência dos turnos. A seguir, o quadro criado por Marcuschi (2002) dá uma visão geral sobre os sinais conversacionais verbais, que se dividem em dois grandes grupos: um que orienta o ouvinte e outro, o falante.

\begin{tabular}{|c|c|c|c|c|c|c|}
\hline & & \multicolumn{3}{|c|}{$\begin{array}{c}\text { QUADRO DOS SINAIS CONVERSACIONAIS } \\
\text { VERBAIS }\end{array}$} & \\
\hline & \multicolumn{2}{|c|}{\begin{tabular}{|l|} 
SINAIS DO FALANTE \\
(orientam o ouvinte)
\end{tabular}} & & \multirow{2}{*}{\multicolumn{3}{|c|}{$\begin{array}{l}\begin{array}{l}\text { SINAIS DO OUVINTE } \\
\text { (orientam o falante) }\end{array} \\
\end{array}$}} \\
\hline & & & & & & \\
\hline \multicolumn{2}{|c|}{ pré-posicionados } & \multicolumn{2}{|c|}{ pós-posicionados } & convergentes & indagativos & divergentes \\
\hline . & 3 & r & & & ex. & ex. \\
\hline $\begin{array}{l}\begin{array}{c}\text { no inicio } \\
\text { de turno } \\
\text { ex. }\end{array} \\
\text { "olha" } \\
\text { "veja" } \\
\text { "bom" } \\
\text { "mas eu" } \\
\text { "eu acho" } \\
\text { "não, năo" } \\
\text { "epa" } \\
\text { "perai" } \\
\text { "certo, mas" } \\
\text { "sim, sei, mas" } \\
\text { "quanto a } \\
\text { isso" } \\
\text { "nada disso" } \\
\text { "você esquece" } \\
\text { "como assim?" } \\
\text { etc. }\end{array}$ & $\begin{array}{l}\text { no inicio } \\
\text { de unidade } \\
\text { comunicativa } \\
\text { ex. } \\
\text { "entäo" } \\
\text { "ai" } \\
\text { "daí" } \\
\text { "portanto" } \\
\text { "agora veja" } \\
\text { "porque" } \\
\text { " e" } \\
\text { "mas" } \\
\text { "assim" } \\
\text { "por exemplo" } \\
\text { "digamos assim- } \\
\text { "quer dizer" } \\
\text { "eu acho" } \\
\text { "como vê" } \\
\text { etc. }\end{array}$ & $\begin{array}{l}\begin{array}{c}\text { no final } \\
\text { de turno } \\
\text { ex. }\end{array} \\
\text { "né" } \\
\text { " certo?" } \\
\text { "viu?" } \\
\text { "entendeu?" } \\
\text { sacô?" } \\
\text { "é isso ai" } \\
\text { "que acha?" } \\
\text { "e então?" } \\
\text { "diga lá" } \\
\text { "é ou não é?" } \\
\text { etc. }\end{array}$ & 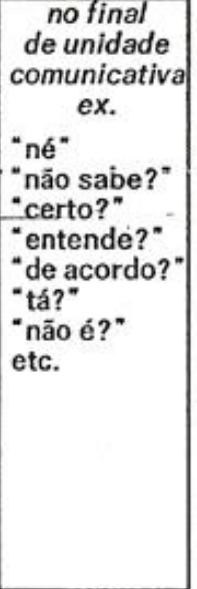 & $\begin{array}{l}\text { "sim" } \\
\text { "ahã" } \\
\text { "mhm" } \\
\text { "claro" } \\
\text { "pois não" } \\
\text { "de fato" } \\
\text { "claro, claro" " } \\
\text { "isso" } \\
\text { "ah sim" } \\
\text { "ótimo" } \\
\text { "tai" } \\
\text { etc. }\end{array}$ & $\begin{array}{l}\text { "será?" } \\
\text { "não diga" } \\
\text { "mesmo?" } \\
\text { "é?" } \\
\text { "ué" } \\
\text { "como?" } \\
\text { "como assim?" } \\
\text { "o quê?" } \\
\text { etc. }\end{array}$ & $\begin{array}{l}\text { "nāo" } \\
\text { "duvido" } \\
\text { "discordo" } \\
\text { "essa nāo" } \\
\text { "nada disso" } \\
\text { "nunca" } \\
\text { "perai" } \\
\text { "calma" } \\
\text { etc. }\end{array}$ \\
\hline
\end{tabular}

Fonte: Marcuschi [12].

Figura 1. Sinas conversacionais verbais

Com base na Figura 1 e nos conceitos vistos até aqui, podem-se relacionar funções, formas e posições, como disposto nos itens abaixo [12]:

- $\quad$ sinais de tomada de turno: são expressões utilizadas para se identificar início ou tomada de turno, como, por exemplo: "olha", "veja”, “bom”, etc.; 
- sinais de sustentação de turno: utilizados, normalmente, pelo falante para manter a posse do diálogo, retomar ou obter a atenção do ouvinte. Normalmente, aparecem no final de uma unidade comunicativa e na forma de indagação, como "acha?", "né?", "ta", etc.;

- sinais de saída ou entrega de turno: estes sinais aparecem no final de turno com o objetivo de repassar o diálogo do falante para o ouvinte, invertendo os papéis. Normalmente aparecem na forma indagativa, aguardando na sequência do outro;

- sinais de armação do quadro tópico: utilizados para sinalizar em que ponto se encontra a conversação, como, por exemplo: "agora que já conversamos sobre isso, podemos falar sobre o tempo";

- sinais de convergência ou divergência: são sinais que, normalmente, aparecem como sobreposição de turno e servem para demonstrar que o ouvinte está prestando atenção ou até mesmo concordando com o falante;

- sinais de abrandamento: normalmente aparecem como forma de atenuar a transmissão de notícias desagradáveis com a intenção de minimizar riscos.

Os conceitos abordados sobre os sinais conversacionais verbais dão um embasamento para o entendimento dos marcadores conversacionais, importantes para uma análise da conversação e para o objetivo deste trabalho.

\section{Marcadores Conversacionais em Ambientes de Comunicação Síncrona}

Dentre as ferramentas de comunicação síncrona disponíveis em comunidades virtuais, acredita-se que o chat seja o recurso mais utilizado, por permitir que os participantes troquem mensagens entre si, de maneira formal ou informal, dependendo do contexto. Em ambos, a utilização de smiles ou emoticons é frequente, principalmente para expressar estados afetivos. Ex: :-) = sorriso, brincadeira; :-( = tristeza, etc.

No diálogo on-line, ou seja, uma conversa em que os participantes digitam sua fala, pode-se encontrar uma linguagem mais informal e cheia de particularidades, como o uso de abreviaturas (ex: blz = beleza, vc $=$ você, $\mathrm{rs}=$ risos, $\mathrm{tc}=$ teclar ), uso de letras minúsculas e maiúsculas de acordo com a intenção do "falante". A objetividade e a rapidez são elementos básicos. Outras particularidades, como a conversa ser compartilhada com todos ou não (reservadamente), estão presentes na utilização dos chats como ferramenta de comunicação.

O chat, por ser produzido via computador, tem como suporte uma escrita reestruturada, portanto, diferentemente do que ocorre em uma conversação realizada face a face. Geralmente no chat são usados períodos curtos e simples, com marcas de envolvimento entre os interlocutores, alto grau de informalidade e descontração, dependendo do contexto é claro, assim como a presença de marcadores conversacionais.

Os enunciados nesse novo contexto, por serem breves e concisos, são expressos por meio de uma escrita geralmente abreviada, sem muitas preocupações com aspectos normativos. Gestos e expressões faciais próprias de uma interação face a face são substituídos por símbolos próprios, que são criados ou copiados a cada momento (emoticons). Por ser extremamente curto o tempo transcorrido entre um pensamento e a escrita de uma palavra ou frase e a sua visualização, o interlocutor precisa de destreza e uma grande agilidade no momento em que está "teclando".

Embora sejam marcas de enunciados, o excesso de pontos de interrogação e exclamação e a ausência de sinais de pontuação e acentuação não chegam a comprometer a compreensão dos mesmos. Além disso, o uso dos emoticons contribui no processo de compreensão dos enunciados, uma vez que se caracterizam como ícones que traduzem as emoções de um interlocutor ao outro.

Segundo [12], o chat poderia ser classificado como um gênero textual, na medida em que a expressão "gênero textual" se refere aos textos materializados que apresentam características sociocomunicativas, definidas por conteúdos, propriedades funcionais e estilo, sendo composto por sequências tipológicas de base. Assim, quando nomeamos certos textos como narrativos, descritivos ou argumentativos, não estamos nomeando o gênero, mas o predomínio de um tipo de sequência de base. 


\section{O Sistema Multiagente do Chat da CV-Muzar}

O termo "agente" é mais aceito pela comunidade científica como um programa de software que auxilia o usuário na realização de alguma tarefa ou atividade [13], sendo dotado de inteligência e autonomia. A autonomia, neste caso, significa que cada agente possui sua própria existência, operando sem a intervenção de humanos ou outros agentes, e tem controle sobre suas ações e seu estado interno.

De acordo com [13], os agentes de software podem ser mais facilmente entendidos se comparados com agentes humanos ou agentes robôs. Um agente pode ser visto como algo que observa o ambiente através de sensores e age nesse ambiente através de atuadores. Comparando, um agente humano possui olhos, ouvidos e outros órgãos para sensoriar o ambiente, assim como mãos, pernas, boca e outras partes do corpo para agir neste ambiente.

Por sua vez, quando existem vários agentes coexistindo num mesmo ambiente e interagindo, é constituída uma sociedade, a qual é denominada de Sistema Multiagente (SMA). O SMA é formado quando há a intenção de alcançar um objetivo em comum com a ajuda de vários agentes operando no ambiente.

Em um SMA a comunicação é fundamental para permitir que haja colaboração, negociação e cooperação entre entidades independentes. Em sistemas multiagentes é necessário que a comunicação seja disciplinada para que os objetivos sejam alcançados efetiva e eficientemente, necessitando, assim, de uma linguagem que possa ser entendida pelos outros agentes presentes no ambiente. Essa comunicação tem como principal objetivo a partilha do conhecimento com os outros agentes e a coordenação de atividades entre agentes, ou seja, deve permitir que agentes troquem informações entre si e coordenem suas próprias atividades sempre num sistema coerente.

No chat da CV-Muzar está sendo implementado um Sistema Multiagente (SMA), o qual consiste em cinco agentes cooperativos para a análise dos diálogos entre os participantes da comunidade nas salas de batepapo. As conversas são monitoradas em tempo real com o objetivo de identificar possíveis déficits no diálogo, como, por exemplo, entradas e saídas de turnos. Nesse caso, os agentes que compõem o sistema podem interferir na interface de conversação para aconselhar e, se necessário, advertir o participante.

O SMA proposto é composto por cinco agentes, cada qual com sua função, a saber:

- AgenteUm: responsável pela solução de problemas simples, como a falta de saudações no início de uma conversa e o controle de tempo entre os turnos do usuário falante e o usuário ouvinte. A identificação destes déficits é realizada por meio de uma análise da base de conhecimento que contém a lista de marcadores que deve ser utilizada durante a conversação. Esta análise é feita pela comparação do que é digitado com o que está armazenado; somente então é proposta uma compensação. Este é o mecanismo utilizado em todas as análises feitas pelos agentes inteligentes.

- AgenteDois: inicia suas ações ao receber uma confirmação do AgenteUm. É responsável por uma verificação mais complexa das frases, como, por exemplo, ausência de marcadores de início e final de turno e pontuação. Para a análise dos marcadores utiliza-se a tabela sugerida por Marcuschi (2002), na qual há uma lista de marcadores pré e pós-posicionados do falante (primeiro turno, que orientam o ouvinte) e uma série de sinais indicadores de convergência, indagação ou divergência usados pelo ouvinte (turno subsequente, que orientam o falante).

- AgenteTres: encarregado de interferir no chat - como se houvesse um terceiro usuário. O AgenteTres adverte sobre as falhas que o usuário cometeu e deve observar a coerência da conversa e, se necessário, confirmar alguma verificação que não coincidiu com nenhuma ocorrência cadastrada no banco de dados de marcadores. Como o objetivo do agente não é realizar uma análise semântica, a coerência é identificada apenas pela verificação do uso dos marcadores conversacionais.

- AgenteQuatro: encarregado de cadastrar informações no banco de dados depois de certo "aprendizado". A aprendizagem é uma característica forte nos sistemas de agentes. Com a ajuda e as confirmações do AgenteTres, será possível conceber ao AgenteQuatro a capacidade de aprendizado e cadastramento de novos déficits e novos marcadores no banco. A aprendizagem do SMA acontece por reforço. A aprendizagem por reforço é, fundamentalmente, uma 
aprendizagem por iteração com o mundo que rodeia aquele que aprende. A principal característica que diferencia a aprendizagem por reforço dos outros tipos de aprendizagem é o fato de esta utilizar informação que reflete uma avaliação (interna ou externa) das ações efetuadas em lugar de diretivas indicando quais são as atitudes corretas e as incorretas.

- AgenteServlet: este agente terá a função básica de monitorar e realizar a comunicação do AgenteTres com o chat e com o AgenteUm, centralizando em um único agente a inferência do mecanismo de intervenção do chat com o usuário.

A comunicação entre os cinco agentes está ilustrada na Figura 2.

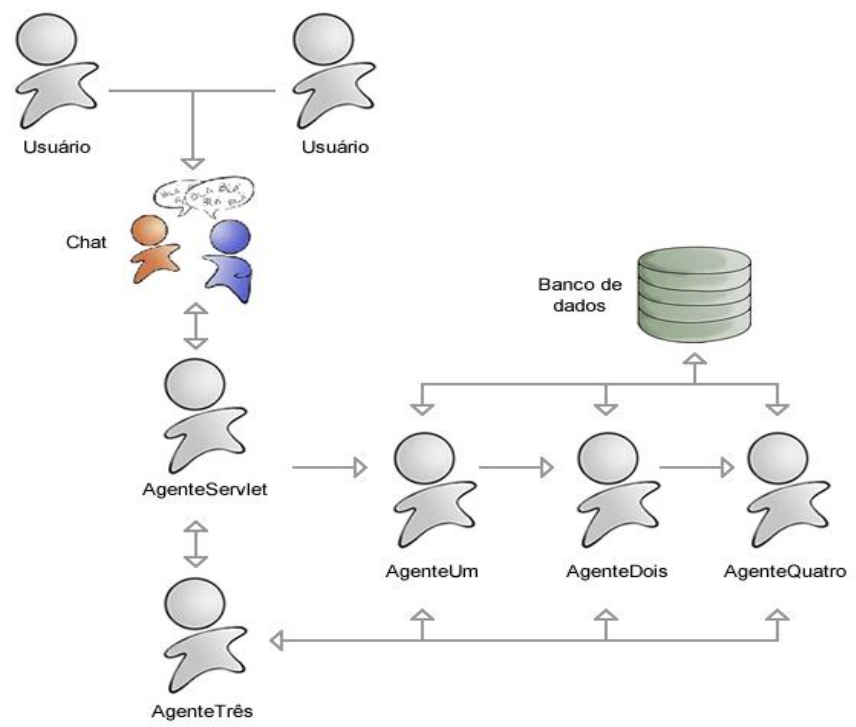

Figura 2. Esquema de comunicação entre os agentes

Para a implementação do ambiente proposto estão sendo utilizados a linguagem Java, a plataforma de gerenciamento Jade e os padrões FIPA para a comunicação dos agentes.

A tecnologia Jade (Figura 3), Java Agent Development, foi desenvolvida durante as pesquisas da Telecom Italia, empresa italiana de telecomunicações; tendo toda sua documentação disponível no site da Telecom Italia Labs (http://jade.tilab.com). O framework Jade mostra-se eficiente no suporte, gerenciamento e monitoração do sistema multiagente, principalmente na parte de comunicação entre cada instância de agente. A comunicação, por sua vez, segue os protocolos FIPA para troca de mensagens entre agentes. FIPA, sigla para The Foundation for Intelligent Physical Agents, é uma organização aceita pela IEEE Computer Society [14] como reguladora de padrões para interação de agentes e sistemas de agentes.

Um sistema baseado em agentes funciona com agentes autônomos executando determinadas tarefas, solicitando tarefas a outros agentes do sistema, ou, até mesmo, controlando o nascimento/morte de agentes menores. 


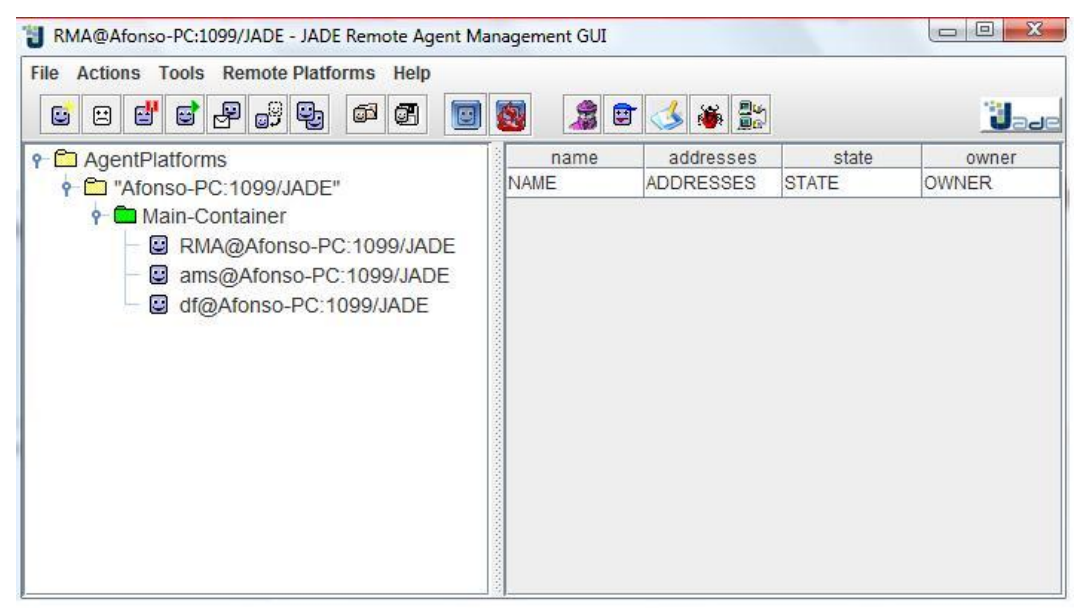

Figura 3. Interface do Jade

$\mathrm{Na}$ plataforma, agentes são iniciados através do método setup() e suas tarefas são determinadas por comportamentos. Cada agente recebe, em seu nascimento, um conjunto de dados identificando o serviço prestado e o local de execução de suas tarefas, bem como, possivelmente, conjuntos de ontologias ou outras características classificatórias no serviço. Aqui, entende-se como característica classificatória qualquer informação que permita ao agente boot da plataforma identificar capacidades específicas de determinado grupo de agentes numa solicitação por determinado serviço ou método.

Juntamente com as características do serviço, o agente pode receber comportamentos. De forma simplificada, esses comportamentos são os programas a serem executados. A diferença é que esta execução pode vir acompanhada de outros comportamentos do próprio agente ou de outros do sistema. Por isso a grande semelhança e a inevitável comparação de agentes inteligentes com agentes humanos.

O ambiente inicial, sendo desenvolvido, conta com os três primeiros agentes; o mínimo necessário para realizar o estudo. O Agente Quatro, em razão de sua complexidade, será desenvolvido posteriormente. Enquanto isso, o cadastro de novas informações sobre marcadores e déficits é feito manualmente.

Assim como em [15], para o desenvolvimento da aplicação foi utilizada uma arquitetura BDI, representada na Figura 4. O modelo BDI considera o estado do agente representado por três estruturas: suas crenças (beliefs), seus desejos (desires) e suas intenções (intentions). Além desses componentes, algumas arquiteturas BDI usam o conceito de planos, que seriam as etapas a serem seguidas, quando gerada uma intenção, para a realização de uma ação sobre o ambiente, a saber: 


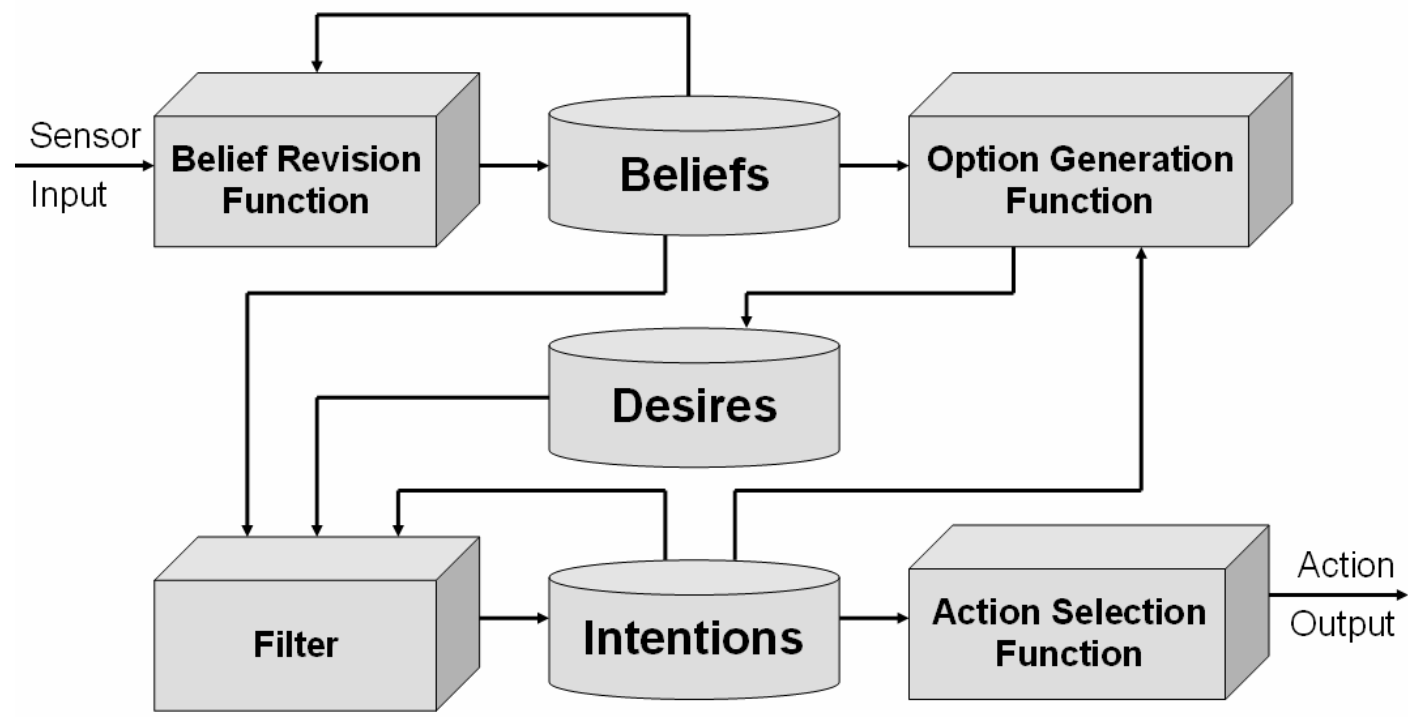

Fonte: Wooldridge (2002).

Figura 4. Diagrama de uma arquitetura BDI genérica

- um conjunto de crenças (Beliefs) atual, representando a informação que o agente tem sobre seu ambiente;

- um conjunto de opções (Desires) corrente, que representa os possíveis planos de ações disponíveis ao agente;

- um conjunto de intenções (Intentions) atual, que representa o foco atual do agente, isto é, aqueles estados que o agente está determinado a alcançar.

Os agentes funcionarão como assistentes pessoais que auxiliam o usuário em suas mais diversificadas tarefas; neste caso, auxiliarão os usuários do bate-papo a interagir com a ferramenta em si e com os outros usuários da sessão, fazendo com que haja interação e o diálogo se torne atraente e desafiador.

Além da mediação do ambiente, é importante que o agente não tire a concentração do usuário no tema debatido; apenas dê algumas dicas e/ou sugestões, fazendo com que o usuário continue com a atenção voltada para o diálogo.

A arquitetura de agentes a ser utilizada para o desenvolvimento do protótipo será do tipo BDI e, para a modelagem, será utilizada a técnica UML.

O agente interferirá sobre o diálogo se alguns destes casos acontecer:

- um usuário não iniciar uma sessão sem as devidas saudações pessoas do tipo oi, olá, bom dia, boa tarde, boa noite, tudo bem, entre outros;

- o usuário ficar durante um tempo considerável sem interagir com os demais participantes;

- na conversa houver palavras inadequadas vindas de algum dos usuários;

- caso haja três participantes e o destinatário comum entre duas pessoas for o mesmo, não está ocorrendo uma interação completa entre os participantes;

- no caso da falta de uso de marcadores.

O agente, ao perceber tais características vindas do ambiente, fará o processamento necessário e agirá de forma pouco intrusiva, apenas orientando os participantes do diálogo como um tutor ou mesmo propondo técnicas de compensação para os déficits apresentados. Estas técnicas são compostas de mensagens enviadas pelos agentes, através de uma intervenção direta do próprio chat, ou seja, uma mensagem de correção propondo uma nova estrutura de texto. 


\section{Considerações finais}

Com base no referencial teórico descrito neste artigo, percebe-se que a comunicação é central para a interação social e pode interferir significativamente no desempenho dos participantes da comunidade.

A conversação é um dos elementos da comunicação em que os interlocutores podem interagir e efetuar trocas que acabarão, normalmente, no desenvolvimento cognitivo. Uma conversação não bemsucedida pode caracterizar dificuldades de sociabilização dentro de uma comunidade, gerando muitas vezes interpretações equivocadas.

Neste sentido, pretende-se com esta pesquisa identificar, pela análise dos marcadores conversacionais do chat da CV-Muzar, os déficits de comunicação existentes nos diálogos. Esta identificação será utilizada para criar uma base de conhecimento que proporcionará aos agentes inteligentes uma intervenção, propondo ao usuário formas de compensação. Este método, principalmente pela análise dos marcadores conversacionais, auxiliará os participantes do bate-papo a manterem a interação e, consequentemente, fazer com que esta ferramenta síncrona de comunicação possibilite resultados mais efetivos.

A análise dos resultados, que permitirá identificar o nível de aceitação do Sistema Multiagente proposto, será viabilizada com o uso da CV-Muzar por participantes vinculados ao Museu Zoobotânico Augusto Ruschi da UPF, seja como colaboradores, seja como visitantes. Tal processo será realizado logo que a etapa de implementação na plataforma Jade for finalizada.

Agradecimentos. Ao Conselho Nacional de Desenvolvimento Científico e Tecnológico pelo apoio por meio do Edital MCT/CNPq 15/2007 - Universal e pela bolsa de Iniciação Científica e à Fundação de Amparo a Pesquisa do Rio Grande do Sul, pela concessão de uma bolsa de iniciação científica.

\section{Referências}

[1] DE MARCHI, A. C. B. (2006). Um ambiente de suporte a comunidades virtuais baseadas em repositórios de objetos de aprendizagem para apoio à aprendizagem informal em museus. Tese (Doutorado em Informática na Educação) - Universidade Federal do Rio Grande do Sul. Porto Alegre: UFRGS, 2006. 225p. .

[2] DE MARCHI, A. C. B.; MORAES, M. C.; TESTA, C. (2009). CV-Muzar using a Multiagent System for groups formation. In: 9th IFIP TC3 World Conference on Computers in Education. Edited by Arthur Tatnall and Anthony Jones.

[3] MONGOOSE TECHOLOGY. (2001) The 12 Principles of Civilization - Guidelines for Designing Interactive Internet Services. Disponível em: <http://www.mongoosetech.com>. Acesso em: 16 ago. 2004.

[4] WATZLAWICK, P.; BEAVIN, J. H.; JACKSON, D. D. (2000). Pragmática da comunicação humana (Pragmatics of human communication). São Paulo: Cultrix.

[5] ORECCHINI, C. K. (1996). Análise da conversação: princípios e métodos (Conversation analysis: principles and methods). Parábola Editorial.

[6] HERRING, S. (1996). Posting in a different voice: gender and ethics in CMC. In: Ess, C. (Ed.). Philosophical Perspectives on Computer-Mediated Communication. Albany: State University of New York Press.

[7] REID, E.M. (1991). Electropolis: Communication and Community on Internet Relay Chat. Thesis (Honours) - University Of Melbourne. Disponível em: <http://eserver.org/cyber/reid.txt>. Acesso em: 14 out. 2005.

[8] RECUERO, R. da C. (2002). Comunidade virtuais no IRC: o caso do \#Pelotas - um estudo sobre a comunicação mediada por computador e a estruturação de comunidades virtuais. Dissertação (Mestrado) UFRGS, Porto Alegre.

[9] LÉVY, P. (1996). O que é virtual? São Paulo: Ed. 24. 
[10] MENEZES, L. Matemática, linguagem e comunicação. (1999). In: PROFMAT99, Portugal. Disponível em: $<\mathrm{http} / / / \mathrm{www} . i p v . p t / m i l l e n i u m /$ Millenium_20.htm>. Acesso em: 14 out. 2005.

[11]FERNBACK, J.; THOMPSON, B. (2005). Virtual communities: Abort, Retry, Failure? Disponível em: $<$ http://www.well.com/user/hlr/texts/VCcivil.html $>$.

[12] MARCUSCHI, L. A. (2002). Gêneros textuais e ensino. Rio de Janeiro: Lucerna.

[13] WOOLDRIDGE, M. (2002). Introduction to Multi Agent Systems. Chichester: Wiley.

[14] IEEE FOUNDATION FOR INTELLIGENT PHYSICAL AGENTS. (2009). Welcome to FIPA!. Disponível em: $<$ http://www.fipa.org/>.

[15]RABELLO, R. dos S. (2008). Interação e autismo: uso de agentes inteligentes para detectar déficits de comunicação em ambientes síncronos. Exame de qualificação (Doutorando em Informática na Educação) Universidade Federal do Rio Grande do Sul, Porto Alegre. 